mentation (or erosion) rate in shallow water (10-200 m), 4) an in situ nephelometer which can be lowered to determine data on particles in the water to $200 \mathrm{~m}$, and 5) a means of quantifying (and at least partly identifying) plankton that is far more rapid and efficient than the present methods.

Finally, we should recall that in some important environmental matters all of our techniques are inadequate. For example, large changes of which we are only vaguely aware take place in the kind and distribution of marine animals as a result of natural changes. A series of violent storms, a shift in the current system, or a few warm water years may influence the sea life far more than any of man's influences. How does one detect man-caused changes against this change in background?

The capability for assessing fish populations is, in most cases, primitive. The population of some fish may not be known within an order of magnitude. How then can their fishery be managed?

The actual effects of oil spills on sea life in open waters is almost completely unknown. Very few measurements in the sea confirm or deny the public concern over large oil spills.

One concludes that there is a great deal of room for new ideas about how to quantify man's effects in the sea.

\title{
Improved Ocean Measurement Capabilities Using Advanced Engineering Technology
}

\author{
JOHN H. CAWLEY
}

\begin{abstract}
Ocean measurement systems for the 1980's will require improved capabilities to sample and measure specific ocean parameters. With the increasing costs of ocean operations, these systems must be designed and produced to yield a higher degree of performance and reliability than has been previously available. Also, new capabilities will be required as program emphasis shifts to the continental shelves and margins where the understanding of coastal processes, energy development and production, ocean waste disposal, and improved water quality are of increasing social and economic importance. Some of the requirements for improved marine measurement systems and how they can be achieved are discussed below.
\end{abstract}

\section{INTRODUCTION}

$\mathbf{T}$ THE COMPLEX investigative programs being planned for the 1980's will require advanced technological developments and new measurement systems with improved capabilities to sample and measure specific ocean parameters. With the increasing cost of operations, these systems must be designed and produced to yield a high degree of performance and reliability which has not been generally available in past programs. A representative listing of in situ sensors, measurement systems, and platforms for deployment of measurement systems is shown in Table I. Many of these measurements will become more critical as national programs and emphasis shift to the continental shelves and margins where coastal processes,

Manuscript received May 1, 1978. This paper was presented at the International Workshop on Ocean Instrumentation, National Academy of Sciences, Washington, DC, May 1-3, 1978.

The author is with National Oceanic and Atmospheric Administration, Office of Ocean Engineering, Rockville, MD 20852.
TABLE I

OCEAN MEASUREMENT SENSOR/SYSTEMS AND PLATFORMS

\begin{tabular}{lcc}
\hline \hline System & $\begin{array}{l}\text { Estimated (1) } \\
\text { development } \\
\text { funds } \$ 000\end{array}$ & $\begin{array}{c}\text { Estimated (2) } \\
\text { development } \\
\text { period - yrs. }\end{array}$ \\
\hline 1. Deep Coring System (100m) & 850 & $2-3$ \\
2. Stable Miulti-Point Mooring & 800 & $7-2$ \\
3. Acoustic/Tel emetry System & 700 & $1-2$ \\
4. Towed/Transiting Particle Counter & 800 & $1-2$ \\
\hline
\end{tabular}

(1) Includes system development costs; test and evaluation, including ship time; complete documentation

(2) Best estimates of senior investigators with broad experience in the design and use of similar systems

energy development and production, and ocean dumping are of increasing social and economic importance.

A variety of new and more reliable sensors and measurement systems will be required if further progress on important scientific and engineering problems is to be made. In some measurement areas, the unavailability of reliable sensors and systems suitable for long-term in situ operation is a limiting factor and advanced engineering development will be necessary if reliable, accurate, and reproducible measurements are to be achieved.

\section{PHYSICAL}

In the upper few meters of the water column, surface waves and turbulence affect available water current instrumentation so severely that current speed and direction measurements cannot be made with conventional instruments with any degree 
of accuracy and reliability. As a result, several innovative approaches are now being considered for surface current and wave measurements. For example, a low-frequency Doppler radar system is in development at the Wave Propagation Laboratory of NOAA's Environmental Research Laboratories and early tests show excellent promise for large-area (2000$\mathrm{km}^{2}$ ) real-time surface current measurement. At other laboratories, profiling current meters that are decoupled from surface buoy mooring motion and several drifting buoy systems are in various stages of development. Also, several different laboratory groups are independently developing the technology for measurement of ocean wave spectra to help determine wave force loading effects and how these factors affect the design of offshore structures.

Physical measurements are required at the ocean/air interface, throughout the water column, and on the ocean floor. Fixed station and moored systems are required where longterm time-series measurements are needed. In other cases, special towed systems will be required to provide rapid and accurate measurement and sampling over large ocean areas. Long-term reliable physical measurements of the ocean/air interface will also be of critical importance, e.g., in the multiyear National Climate Program for which NOAA would have the lead Agency responsibility.

\section{BIOLOGY AND WATER QUALITY}

Biological and water quality assessments are still dependent on periodic water and sediment samples. In almost all cases, these samples are analyzed in laboratories, aboard a research vessel, or elsewhere ashore, and require large amounts of technician time. With few exceptions, reliable and accurate in situ biological and chemical instrumentation is not generally available although essential for reliable long-term monitoring purposes. For example, biological assessments still require a separation, counting, and classification operation which is done manually. Laboratory chemical analysis also requires large amounts of technician time since few reliable in situ water quality sensors and systems are available.

Particle counting and sizing systems which can be towed at various depths by research vesseIs are required for rapid, largearea assessments for fish stock and for related studies. A variety of reliable chemical sensors need to be developed for in situ measurements. For example, dissolved oxygen, hydrocarbon, and heavy metal sensors exhibit an unacceptable drift when operated in situ and are not suitable for uninterrupted long-term monitoring applications. Increased emphasis on sensor development and evaluation is clearly required if reliable in situ marine water quality instrumentation is to be available in the critical period just ahead.

\section{GEOLOGICAL AND GEOPHYSICAL}

Marine geological and geophysical research in the deep oceans has advanced the understanding of the geological processes of the ocean floor. This research depends on the development of analytical models to stimulate some of the key physical processes that are believed to take place. Sensitive instrumentation mounted on the ocean floor is used to measure seismic disturbances, heat flow, pore pressure, and shear strength, and to take soil cores and surface sediment samples. These measurements and samples are used to test analytical models and to determine some of the important engineering properties of the sea floor.

Research emphasis has recently been shifting from exploration in the deep ocean to development of the continental shelves and margins. As a consequence, there is now a pressing need for a basic understanding of the in situ engineering properties of the marine sediments. Research programs should include improved and more reliable instrumentation and test procedures, advanced coring techniques, and laboratory testing. Properties of marine sediments such as creep strength, shortterm shear strength, liquefaction, and change of strength and material properties under dynamic and static loading conditions, must be measured and improved sensors developed. Advanced instrumentation and improved techniques are required to determine realistic static and dynamic load limits. There is a need for improved deep-core (100-m) sampling equipment and for techniques to provide undisturbed soil samples for laboratory testing. Successful research efforts will provide the data and models necessary to help improve the reliability of marine structures now being constructed in deeper shelf waters and for the detailed assessment of deep ocean areas for possible disposal of waste materials.

\section{NEW MEASUREMENT CAPABILITIES AND REQUTREMENTS}

In the 1980's, platform and labor costs are expected to continue to increase. As a result, new and improved measurement and sampling equipment will be required if more reliable performance is to be provided at a lower overall cost per data point. A key design goal of these advanced systems will be data comparability and quality assurance to avoid some of the pitfalls of previous developments. Table II lists examples of four conceptual measurement systems which would require substantial design and development resources. None of these measurement systems require new technology. However, each requires substantial engineering development and documentation as well as extensive testing and evaluation before being ready for routine operation at sea.

1) The corer would be designed to provide cores $4-6$ in in diameter to soil depths of $100 \mathrm{~m}$. This is approximately three times the length of the longest core that is currently taken from a research vessel. The longer cores are needed for scientific investigations and also to substantiate bottom foundation conditions for offshore platforms placed in deep continental shelf (1000-ft) waters. A special corer design will be required to provide for penetration to depths beyond about $30 \mathrm{~m}$ where the shear strength of the soils exceeds about 600 $\mathrm{gm} / \mathrm{cm}^{2}$. The anticipated test and evaluation of such a system would require research vessel time at between 5000 and 7000 dollars per ship-day and is a major factor in determining overall costs. Approximately six weeks of ship time would be necessary for a series of test deployments of the new apparatus.

2) Multipoint moorings would provide for stable instrumen- 
TABLE II

EXAMPLES OF ADVANCED TECHNOLOGY DEVELOPMENT REQUIREMENTS

\begin{tabular}{|c|c|c|c|}
\hline & 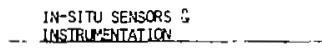 & $\begin{array}{l}\text { MEASUREMENT } \\
\text { SYSIEMS }\end{array}$ & PLATEONS \\
\hline AMSICH & 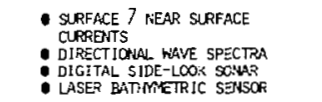 & $\begin{array}{l}\text { FIXED } \\
\text { IN SITU RECOVERABLE } \\
\text { MOCFED EXPEALE }\end{array}$ & $\begin{array}{l}: \text { SHIPS } \\
\text { TOMED } \\
\text { SATELITITE } \\
\text { AIRCRATT }\end{array}$ \\
\hline BIOHOGICAL & $\begin{array}{l}\text { - PARTICLE COUNTER } \\
\text { PARTILE SIZEPS } \\
\text { - CHLOROPHU A,B,C } \\
\text { TRBIDITY METER }\end{array}$ & - TOMER & : SHIPS \\
\hline OFElices & $\begin{array}{l}\text { - STABLE LONG TEFY: SEISORS } \\
\text { - DO \& PH } \\
\text { - TOXIC METALS } \\
\text { - BOD \& CCD } \\
\text { - HTROCARBONS }\end{array}$ & 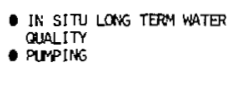 & $\begin{array}{l}\text { SHIPS \& BUOYS } \\
\text { TONDD } \\
\text { FIXeO }\end{array}$ \\
\hline $\begin{array}{l}\text { EOLGICAL } \\
\text { EIPHSICAL }\end{array}$ & $\begin{array}{l}\text { - BOTTOM CONPOSITICN } \\
\text { - RELIASLE SEIMGN TRAP } \\
\text { - SEDIIERT GRAIH SHAPE \& SIZE } \\
\text { - SHEAR STRENGTH } \\
\text { - PORE PRESSURE }\end{array}$ & $\begin{array}{l}\text { REOOTE MANIPULATOR } \\
\text { SIUPYERS IRIF } \\
\text { DEEP CORINIG (IOOM) } \\
\text { - RECONERABLE }\end{array}$ & $\begin{array}{l}\text { SHIPS } \\
\text { TOWDD } \\
\text { FREE }\end{array}$ \\
\hline
\end{tabular}

tation platforms in deep waters. Such moorings would also provide a high degree of isolation from movement in the mooring caused by surface waves, swells, and subsurface currents. Several complex moorings of this type have been deployed by the Navy for special acoustic studies. WHOI recently designed and successfully deployed a tri-mooring for the study of internal waves; however, there is as yet no available design suitable for routine deployments in deep waters.

3) A sea floor measurement and acoustic telemetry system would provide for a sea floor instrument package in deep waters and an acoustic telemetry link to a subsurface buoy which is hardwired to a surface spar buoy. A major difficulty in this development is to determine how to decouple the spar buoy from the subsurface buoy in heavy seas. Analytical modeling and simulation studies would be required as well as full-scale tests at sea. Although several studies have been made of such systems, there are no satisfactory solutions at hand. However, a successful system could make use of a satellite communication link to control stations ashore to provide sea floor seismic information and other data important to sea floor engineering studies.

4) The detection, counting, and sizing of small particles in situ has become increasingly important to zooplankton studies. At present, these studies require very heavy commitments of technician time in the laboratory to identify, size, and count small particles collected in net samples at sea. Analysis of a single sample may take up to eight man-hours. Devices need to be developed for sorting particles by size both within shore base laboratories and at sea. An effective development program will be required which will use readily available technology. NOAA's Northeast Fisheries Laboratories and the NOAA Office of Ocean Engineering in Washington, DC, are now commencing studies involving computer-aided patternrecognition technology which is aimed at the automatic counting and sizing of zooplankton for routine fishery investigations. This development is right at the edge of the state of the art and a great deal of work will need to be done before a system is available for routine fishery assessments.

\section{A RECOMMENDED APPROACH}

In the United States, new oceanographic measurement and data-acquisition systems (DAS's) are generally funded and developed as a component part of major scientific programs. Only on isolated occasions has separate "up-front" funding been provided for the separate development of marine measurement and sampling systems and other technology needed to meet advanced marine measurement requirements. In instances where programs were initiated specifically for development of major systems, e.g., the Monster Buoys-developed by General Dynamics Corporation for the Office of Naval Research, or the Vector Averaging Current Meter (VACM)developed at Woods Hole Oceanographic Institution and manufactured by AMF Corporation, the programs have been highly successful and the products of these development efforts have been widely accepted in both the public and private sectors. Most importantly, the end products are not tied to particular scientific programs but are broad-based with a multitude of applications. However, to be successful, engineering development programs such as these require specific project funding and a dedicated management team fully responsible for the development of advanced ocean measurement and DAS's and not tied to a specific scientific program. We are all familiar with this type of approach since it was central to the Apollo program and other major space programs of the 1960's.

In summary, the oceanographic community must recognize the need for explicit funding for advanced ocean engineering development programs. Also required is a management structure which has the necessary funding flexibility to deal with the conflicting technical requirements of the user communities. Until such management and funding flexibility is established, it is unlikely that the improved performance and reliability required of future marine measurement and DAS's will be fully realized. 